\title{
Based on Intelligent Robot of E-business Distribution Center Operation Mode Research
}

\author{
Juntao $\mathrm{Li}^{1}$, Jie Zhu ${ }^{2}$, Yingying Geng ${ }^{3}$ \\ ${ }^{1,2}$ Information of school, Beijing WUZI university, Beijing, China \\ ${ }^{3}$ department of information and Logistics , Beijing College of Finance and Commerce, Beijing, China
}

\begin{abstract}
According to E-business distribution center operation mode in domestic and advanced experience drawing lessons at home and abroad, this paper based on intelligent robot researches E-business distribution center operation mode. And it proposes the innovation logistics storage in E-business and sorting integration system, and elaborates its principle, characteristics, as well as studies its business mode and logistics process, and its parameters and working mode of AGV equipment.
\end{abstract}

Keywords: E-business distribution, operation mode, Intelligent Robot, AGV equipment

\section{INTRODUCTION}

With the surge of e-commerce business, the logistics center operation mode also grows more. In the device, tedious manual activities are replaced by automation equipment gradually; In the system, the information level grows, and information technology gradually become an modern important symbol in distribution center; In each link of the operation mode, all kinds of new modes emerge in endlessly, such as electronic tags, RF and voice patterns, which brings convenience to choose operation.

However, neither the update of the equipment nor the operation mode can change the current situation, which employees need go around to picking area several times just to pick commodity. In the final sorting link and the chosen that can mostly reflect automation, also stores link with multifarious gauge product is always the bottleneck of e-business distribution center link. The system gives differentiates specific action such as picking to the employees processing, and the process of finding and handling to the AGV.

\section{BASED ON INTELLIGENT ROBOT OF INTRODUCTION OF E-BUSINESS DISTRIBUTION CENTER OPERATION MODE}

\subsection{E-business Logistics Principle of Storage and Sorting Integration System}

In integration system operation mode, mobile automatic warehouse robot has been chosen to assist to shelves and chosen during warehousing that integrates warehousing and chosen, and to be the mode of "goods movement well man still". Warehouse robot make automatic for shelves and handling path according to the instructions, until he finished the whole inventory in the intersections automatic sorting and selection tasks. Operators wait for arrival at node racks and complete picking goods inside the shelves, all the begins and ends controlled by the button. The strong background warehouse management system and identification of innovative landmark qr code makes all these activities .

\subsection{E-business Logistics Characteristics of the Storage and Sorting Integration System}

As for the operation mode, this system breaks the traditional partition mode for storage and sorting, and now the warehouse and sorting mode works at the same area with the same equipment. And the operation mode is changed from "person to goods" to "goods to person". The advantage is innovates the operation mode, reduces the function area, improves the working efficiency, and meets the requirements of the customer experience.

As for the operation form, instead of the employee patrol path distribution center in the form of a circle in accordance with the traditional plan, storage and sorting integration system distributes early job of pathfinding, handling, and etc. to the AGV, and the end chosen and the specific actions to a human, which uses equipment and manpower reasonable, at the same time enhances the automation of the operation. 


\section{E-BUSINESS LOGISTICS MODE FOR STORAGE AND SORTING INTEGRATION SYSTEM}

\subsection{E-business Logistics Storage and Sorting Integration System Analysis of Business Mode}

Figure 1 shows layout diagram of distribution center of this mode. The operator only need to stay in the ends of the storage or chosen mouth, and according to the instructions, intelligent robot goes through the shelves channel around in an orderly fashion, takes out the requirements to appointed warehouse mouth. Then, intelligent robot transports the shelves to the initial place. This mode improves the e-business distribution center automation operations.

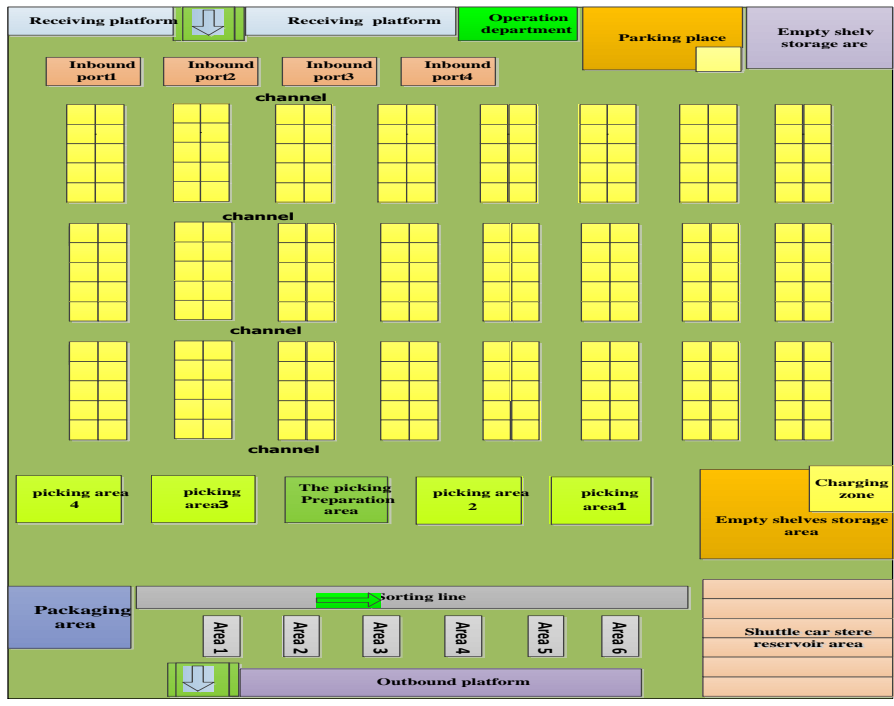

Figure 1: General layout diagram of distribution center

\subsection{E-business Logistics Storage and Sorting Integration System Design of Logistics Process}

\subsubsection{The Warehousing Process Design}

In storage stage, after receipt the goods according to the receiving platform, belt conveyor transports it to the nearest platform. When scheduling system is input inventory, the scheduling system does putaway task arrangement and priority scheduling. The warehouse operators give inbound calls in a way of scanning the goods by handheld RF in the operating terminal. Then scheduling system schedules the nearby AGV. Though the instruction and runs below the shelves ,the AGV itself identifies the required shelves. After lifting the shelves, the AGV carries it to the specified warehousing location.

\subsubsection{The Picking Process Design}

In chosen stage, first of all, order processing system optimizes the orders according to the time window, namely a batch of orders in the specified time interval is processed, do operation in the orders for such as similarity comparison and classification, aimed at improving the chosen order coverage that the same goods in the shelf, and reducing the extra reciprocating motion of the AGV to improve the picking efficiency.

In the chosen preparing area, according to the picking orders' number of each choose mouth every time, as well as the order of picking orders optimized by the system, operators distribute order boxes, and code label for the order boxes corresponding to the order number. When select the appropriate order box to save the material, the characteristics such as size, volume, etc. of the product can be a reference. After it, scanning the label to ensure to system that labeling is completed. Then the shelves can be used by dispatch system. According to the demand, the system schedules the nearest AGV car to carry labeling completed shelves to the appropriate chosen position.

When optimized picking orders are input system, workers will call the picking task in the form of starting the screen bottom button in the chosen terminal. Then the system schedules nearby AGV car according to the call signal, the car runs to the choosing preparation area according to the instruction to handling labeled shelf to choose appropriate location in order. If there is a shelf in operating, the car waits until replace it.

\subsubsection{Requirements for AGV Working Mode and Storage Shelves Design of E-business Logistics Storage and Sorting Integration System}

The basic parameters set of the car are shows as Table 1:

Table 1: Parameters requirements for the AGV car

\begin{tabular}{ll}
\hline $\begin{array}{l}\text { Parameters name of } \\
\text { AGV car }\end{array}$ & Parameter requirements \\
\hline size & $750 * 600 * 425 \mathrm{~mm}$ \\
Self-weight & $<=200 \mathrm{~kg}$ \\
load-bearing & $>=1000 \mathrm{~kg}$ \\
No-load speed & $1.2 \mathrm{~m} / \mathrm{s}$ \\
Loading speed & $1 \mathrm{~m} / \mathrm{s}$ \\
Lifting time & $3-5 \mathrm{~s}$ \\
Lifting way & Body rotating and lifting in one spot \\
Turning way & Steering in situ, body rotation while shelves \\
still \\
Turning radius & $\begin{array}{l}\text { The longest distance between steering shaft } \\
\text { axis to the car body }\end{array}$ \\
\hline
\end{tabular}

Based on this mode as well as the parameters requirements of $\mathrm{AGV}$, structure design renderings of $\mathrm{AGV}$ is shown in fig. 2. Fig. 3 shows the schematic diagram of shelves.

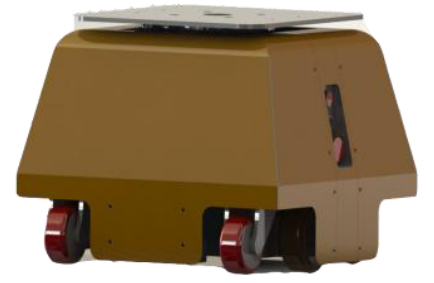

Figure 2: The structure design of $\mathrm{AGV}$ 


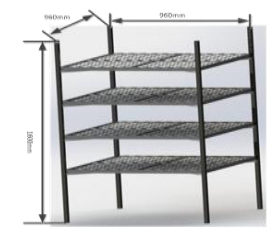

logistics technology, no.2, pp.89-91, 2010.

Figure 3: The schematic diagram of shelf

\section{CONCLUSIONS}

This paper proposed an innovation of storage and sorting integration system in e-business logistics. The system has broken the traditional partition mode, and makes a reasonable combination of automation and artificial mode. It allocates more standardized operations such as handling, storage to automation robot, and the manpower concentrates on unique individual and different picking link of the end of the ecommerce industry, which both improves the working efficiency and saves labor resource, that makes the mode of distribution centre operation more humanized.

\section{ACKNOWLEDGMENT}

This paper is supported by the Funding Project for Technology Key Project of Municipal Education Commission of Beijing (the grant number TSJHG201310037036); Funding Project for Program of Municipal Education Commission of Beijing (the grant number SM201110037004); Funding project for Beijing Key Laboratory of Intelligent Logistics System; Funding Project of Construction of Innovative Teams and Teacher Career Development for Universities and Colleges Under Beijing Municipality(IDHT20130517); Beijing Municipal Science and Technology Project (Z131100005413004).

\section{REFERENCES}

1. Shen Changpeng. Research of order adaptation problem of the structure and the picking system [D], Shandong University, 2011

2. Nie Feng. Research of control method and optimal scheduling of shuttle car system in automated multi-layered storehouse [D], Taiyuan University of science and technology, 2009.

3. Li Jingbin. Research and design of Cigarette dense storage and sorting integration system [D], Shandong University, 2012.

4. Luna, R., and Bekris, k. The Efficient and complete centralized multi - robot path planning. In Proc. of the IEEE/RSJ Int. Conf. On Intelligent Robots and Systems (IROS), 2011.

5. Li Zhe. Research of chosen list processing and path optimization in Logistics center [D], Dalian maritime University, 2011

6. Li Shizhen, Distribution center order batch picking mode and seeds heuristic algorithm [J], lifting transportation machinery, no.1, pp.45-47, 2009.

7. Wei bin and Ji Shouwen, etc. Distribution center layout and equipment configuration optimization simulation $[\mathrm{J}]$, 